\title{
Erratum to: Exercise training in adverse cardiac remodeling
}

\author{
Dirk J. Duncker $^{1}$ • Elza D. van Deel ${ }^{1} \cdot$ Monique C. de Waard $^{1,3} \cdot$ Martine de Boer $^{1}$ • \\ Daphne Merkus ${ }^{1}$. Jolanda van der Velden ${ }^{2}$
}

Published online: 25 November 2015

(C) Springer-Verlag Berlin Heidelberg 2015

Erratum to: Pflugers Arch - Eur J Physiol (2014) 466:1079-1091

DOI 10.1007/s00424-014-1464-8

The original publication of this article contains a mistake. In the pdf-version on page 1080, left column, first paragraph, line 3, (or else in the second paragraph in the introduction starting with): "In contrast to pathological LV remodeling, physiological LV remodeling that is produced by regular dynamic exercise is associated with a decreased risk for coronary artery disease and heart failure [37], an increased myocardial perfusion capacity [9],)".

The authors cited reference [9] inadvertently by mistake; the correct reference is:

Laughlin MH, Bowles DK, Duncker DJ: The coronary circulation in exercise training. Am J Physiol Heart Circ Physiol 2012;302:H10-H23.

The online version of the original article can be found at http://dx.doi.org/ 10.1007/s00424-014-1464-8.

Dirk J. Duncker

d.duncker@erasmusmc.nl

1 Division of Experimental Cardiology, Department of Cardiology, Thoraxcenter Erasmus MC University Medical Center Rotterdam, PO Box 2040, 3000 CA Rotterdam, The Netherlands

2 Laboratory for Physiology, Institute for Cardiovascular Research, VU University Medical Center, Amsterdam, The Netherlands

3 Present address: Department of Intensive Care Medicine, Institute for Cardiovascular Research, VU University Medical Center,

Amsterdam, The Netherlands 